\title{
Media Review • Revue DeS MÉdiaS
}

PDQ: Evidence-Based Principles and Practice. Ann McKibbon, with Angela Eady and Susan Marks. 1999. 212 pp. BC Decker Inc., Hamilton, London, St. Louis. 212 pp. $\$ 42$ (includes CD-ROM). ISBN 1-55009-118-2

T periodically search the shelves of the 1 McMaster University book shop in hopes of finding that literary gem that will teach me everything there is to know about clinical epidemiology and evidence-based medicine. While on a routine book store cruise I was immediately attracted by the big white $P D Q$ title of this book.

Some of you may be familiar with the $P D Q$ (Pretty Darned Quick) Series. I confess: I like this series. The books are short, easy to read, informative and, in some cases, humorous. So that's what attracted me to this book.

The reason I bought the book was the author's name. I recognized the author as the internationally awarded librarian/ researcher who teaches (among other things) the "Panning for Gold" seminars on literature searching. I was fortunate enough to take one of her courses a few years ago and have since saved countless hours on literature searching.

I haven't yet thought of a better title for the book, but the current one - $P D Q$ : Evidence-Based Principles and Practice - is inadequate. Although the author has covered the EBM topic extremely well in very little space, much of this information can be found in a number of publications.

What makes this book so valuable is the information on medical literature databases and search strategies. This is information not readily available any- where. Furthermore, each chapter contains real and hypothetical examples of clinical problems, MEDLINE hedges, as well as search "assignment" exercises, with solutions offered on the accompanying CD-ROM.

I've already read this book twice in the past 6 months and, with just over 200 pages, it doesn't take long. I keep the book within arm's reach as a reference text for good reason. For any researcher or clinician it is definitely a worthwhile investment. For the physician wishing to develop EBM skills, this book is a great place to start.

\section{Andrew Worster, MD}

Research Coordinator

Division of Emergency Medicine

Hamilton Health Science Corporation

Hamilton, Ont.

a.worster@bigfoot.com

The Physician's Corner is your professional area in the Alzheimer Society's Web site.

It is designed to provide the latest information to help physicians diagnose Alzheimer Disease.

It offers doctors practical ways to give care and support to people with the disease and their families.

Through an interactive forum,

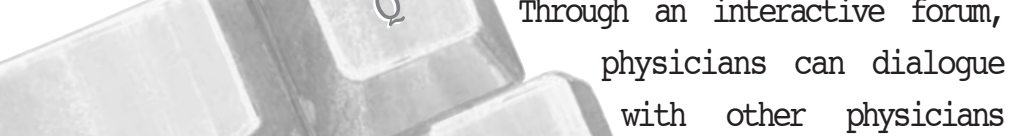

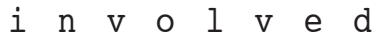
in the treatment of this disease.

\section{Help for Today. Hope for Tomorrow.}

